\title{
Penile Vascular Disorder
}

National Cancer Institute

\section{Source}

National Cancer Institute. Penile Vascular Disorder. NCI Thesaurus. Code C35218.

A non-neoplastic or neoplastic disorder that affects the blood vessels of the penis.

Representative examples include atherosclerosis, venous leak, and hemangioma. 